\title{
THE COULOMETRIC TITRATION OF ACIDS AND BASES IN m-CRESOL MEDIUM
}

\author{
M. BOS and E. A. M. F. DAHMEN
}

Department of Chemical Technology, Twente University of Technology, Enschede (The Netherlands) (Received 2nd April 1974)

Coulometric titrations in non-aqueous solvents offer some distinct advantages over conventional titrations. First of all, it is possible to generate and use titrants which are unstable on storage. Moreover, the method is somewhat more sensitive: coulometric titrations can be carried out in the microequivalent range. There is no need for standardization of titrants, and the titration curves show better resolution because of the absence of dilution effects. Finally, coulometric titrations can easily be automated, as the parameters which control the titration are electrical.

However, several difficulties are involved in coulometric titrations in nonaqueous solvents. High cell resistances necessitate the use of high voltage sources and even with these the currents that can be obtained are generally low. The separation of the anode and cathode compartment of the cell when non-aqueous solvents are used can also be a problem. For liquids with a high viscosity, sintered glass discs are adequate but with other solvents loss of current efficiency can occur. Ion-exchange membranes which are very satisfactory for this purpose when water is the solvent ${ }^{1}$, usually have too high resistances in organic media. When the course of a titration is followed by potentiometry with the glass electrode, as is mostly the case for the titration of acids and bases, sometimes the slow response of the glass electrode ${ }^{2}$ makes rapid titrations impossible. Moreover, when the glass electrode is used, the generating current affects the $\mathrm{pH}$ reading. By proper cell design this effect can be minimized, but it is very difficult to overcome completely.

Many non-aqueous solvents have already been used for coulometric acidbase titrations, e.g. acetic acid/acetic anhydride ${ }^{3.4}$, isopropanol ${ }^{5}$, acetonitrile ${ }^{3.6}$, tert-butano $1^{7}$ and tetrahydrofuran ${ }^{8}$. For tert-butanol and tetrahydrofuran-solvents of relatively low dielectric constant-it was necessary to add $0.2 \%$ water to generate base with $100 \%$ current efficiency ${ }^{7.8}$. When homoconjugation of the compound to be titrated can be expected, the use of solvents with relatively low dielectric constants can be advantageous, as this phenomenon has only a small influence on the accuracy of the titrations in these solvents ${ }^{9}$. However, the necessity of adding water nullifies this advantage, owing to decreased sharpness of the end-points.

In the present study, m-cresol (dielectric constant 12.3) was chosen as the solvent as it was expected that the electrogeneration of base would be possible from the solvent itself. Moreover, $m$-cresol is a good solvent for various types of compounds, i.e. polymers like "Terlenka". A study of the anodic oxidation of 
bases in $m$-cresol ${ }^{10}$ has shown that the determination of bases in $m$-cresol is possible by constant-potential coulometry. In coulometric titrations, the working electrode potential cannot be kept constant, as this would give rise to prohibitively long electrolysis times. Normally, coulometric titrations are run at constant current. Without precautions, the potential of the working electrode varies during the titration under these circumstances, which means that side reactions and loss of current efficiency can occur. To prevent this an excess of a very weak base can be added. For this purpose $0.2 M$ urea was added to the supporting electrolyte.

EXPERIMENTAL

Chemicals

$m$-Cresol (Baker. polymer characterization solvent) was purified by distillation (b.p. $\left.201-201^{\circ} \mathrm{C}\right)$, drying for $24 \mathrm{~h}$ on molecular sieves $(3 \AA$, Union Carbide) and a second distillation (b.p. $201-202^{\circ} \mathrm{C}$ ). The product was used within a day of preparation. The water content was below $0.002 \%$ (Karl Fisher titration).

Tetraethylammonium perchlorate (TEAP, Eastman Kodak) and tetramethylammonium chloride (Eastman Kodak, reagent grade) were recrystallized from ethanol and dried in vacuo at $40^{\circ} \mathrm{C}$ before use.

2,4-Dinitrobenzenesulfonic acid (Eastman Kodak, reagent grade), benzenesulfonic acid (Riedel de Haen), trishydroxymethylaminomethane (Merck, Zur Analyse), picric acid (Merck, Zur Analyse). bromochlorophenol blue (Merck, Indikator), strychnine (Merck, Purum), ioauacetic acid (Merck, Zur Analyse), tribenzylamine (Eastman Kodak), 1,3-diphenylguanidine (Eastman Kodak), nbutylamine (Fluka, puriss.), triethylamine (Koch Light, puriss.) and tetramethylguanidine (Eastman Kodak, pract.) were used as received. Solutions of the acids in m-cresol were standardized against trishydroxymethylaminomethane (Merck, Urtitersubstanz). Solutions of the bases in m-cresol were standardized by titration with hydrochloric acid.

\section{Apparatus}

The coulometric titrations were carried out at room temperature in an $\mathrm{H}$-type cell of which the titration compartment had a content of about $30 \mathrm{ml}$. The working electrode consisted of platinum gauze (area $4 \mathrm{~cm}^{2}$ ). A platinum wire was used as auxiliary electrode. The course of the titration was followed by potentiometry with a glass electrode (Ingold, type $\mathrm{HA} 205$ ) and an $\mathrm{Ag} / \mathrm{AgCl}$ reference electrode filled with $0.1 M$ tetramethylammonium cnloride in m-cresol. A salt bridge with $0.1 M$ TEAP in $m$-cresol was inserted between the reference electrode and the test solution. These electrodes were connected to a $\mathrm{pH}$ meter (Radiometer, type PHM 28). A Philips recorder (PM 8100) was used to record the titration curves. The electrolysis current was delivered by a Metrohm constant-current coulometer (type E 211).

Current integration was done with an electronic integrator constructed from a Keithley operational amplifier type $\mathrm{K} 301$. A schematic diagram of the equipment is given in Fig. 1.

Coulometric titration of acids

The bridge section and the auxiliary electrode compartment of the coulometric 


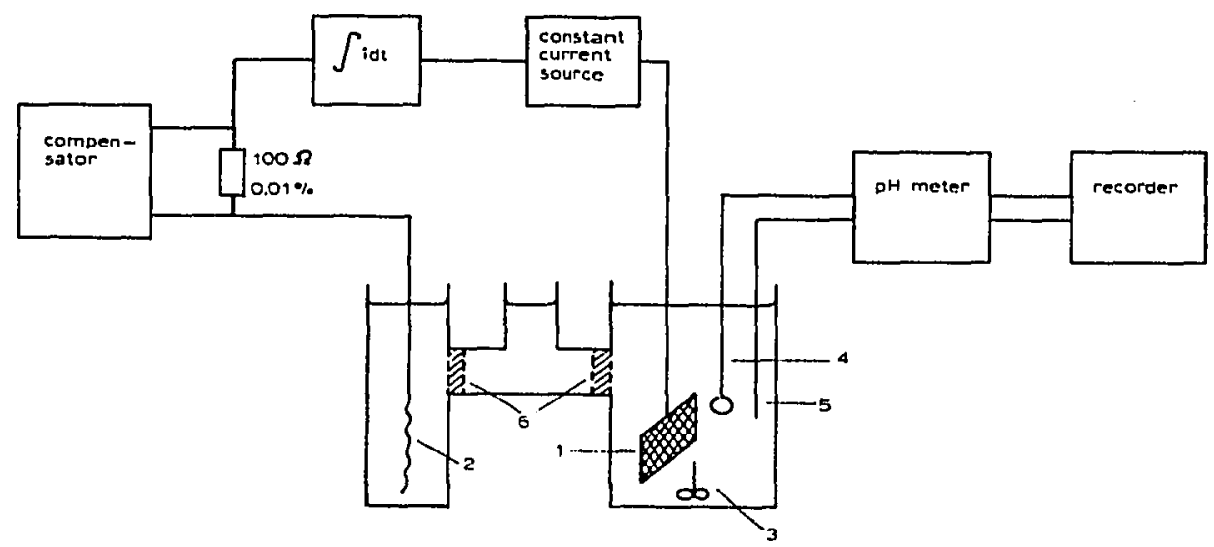

Fig. 1. Schematic diagram of the equipment for coulometric titration of acids and bases in m-cresol. (1) Working electrode, (2) auxiliary electrode. (3) stirrer, (4) glass electrode. (5) $\mathrm{Ag} / \mathrm{AgCl}$ reference clectrode, (6.7) G4 sintered glass disk.

cell were filled with $1 M$ TEAP in $m$-cresol. The titration compartment of the cell was filled with $15-20 \mathrm{ml}$ of $0.1 M$ TEAP in m-cresol. After insertion of the electrodes, the glass electrode was equilibrated for $10 \mathrm{~min}$ in the solution. Then the acid sample dissolved in m-cresol $(0.5-3 \mathrm{ml}$ of $0.01 \mathrm{~N})$ was introduced from a piston burette. The titration was started when the $\mathrm{pH}$ meter gave a stable reading, by switching on the current (working cathode) and simultaneously starting the recorder. During titration the current $i(A)$ was monitored by a compensating galvanometer with an accuracy of $\pm 0.01 \%$. From the recorded titration curve, the time $t(\mathrm{~s})$, necessary to reach the equivalence point was determined. The amount of acid present in the sample was calculated from the formula:

$$
\text { eq. } \text { acid }=t i / 96500
$$

The cell was cleaned and refilled after each determination. When not in use, the glass electrode was stored in aqueous buffer $\mathrm{pH} 7$.

\section{Coulometric titrations of bases}

For the coulometric titration of bases, a somewhat different procedure was followed. The working electrode was operated as the anode. The cell fillings were the same, except the filling of the titration compartment. Here $0.1 M$ TEAP with $0.2 M$ urea in $m$-cresol was used. After the 10 -min equilibration period for the glass electrode, a small amount of sample was introduced in the titration cell and a test titration was started when the $\mathrm{pH}$ meter showed a stable reading. From the recorded titration curve, the $\mathrm{pH}$ value in the equivalence point was determined. By changing the polarity of the working electrode and the auxiliary electrode and switching on the current again, the $\mathrm{pH}$ of the solution in the titration compartment was brought back to the value of the equivalence point. Then a sample of base dissolved in $m$-cresol was introduced from a piston burette $(0.5-3 \mathrm{ml}$ of $0.01 \mathrm{~N})$. The actual titration was performed with the working electrode as anode in the circuit. In the vicinity of the equivalence point, the current was decreased and finally stopped when the $\mathrm{pH}$ of the solution reached the $\mathrm{pH}$ value of the 
equivalence point. Then the integrator was read and the amount of base present in the sample was calculated from the formula

$\therefore \quad$ éq. base $=Q / 96.500$

where $Q$ is the in tegrator reading in coulombs. Up to 4 determinations were made with the same cell fillings.

RESULTS

Titration of acids

A typical coulometric titration curve is given in Fig. 2 for the titration of $6.85 \mu$ eq of 2,4-dinitro benzenesulfonic acid. To determine the standard deviation
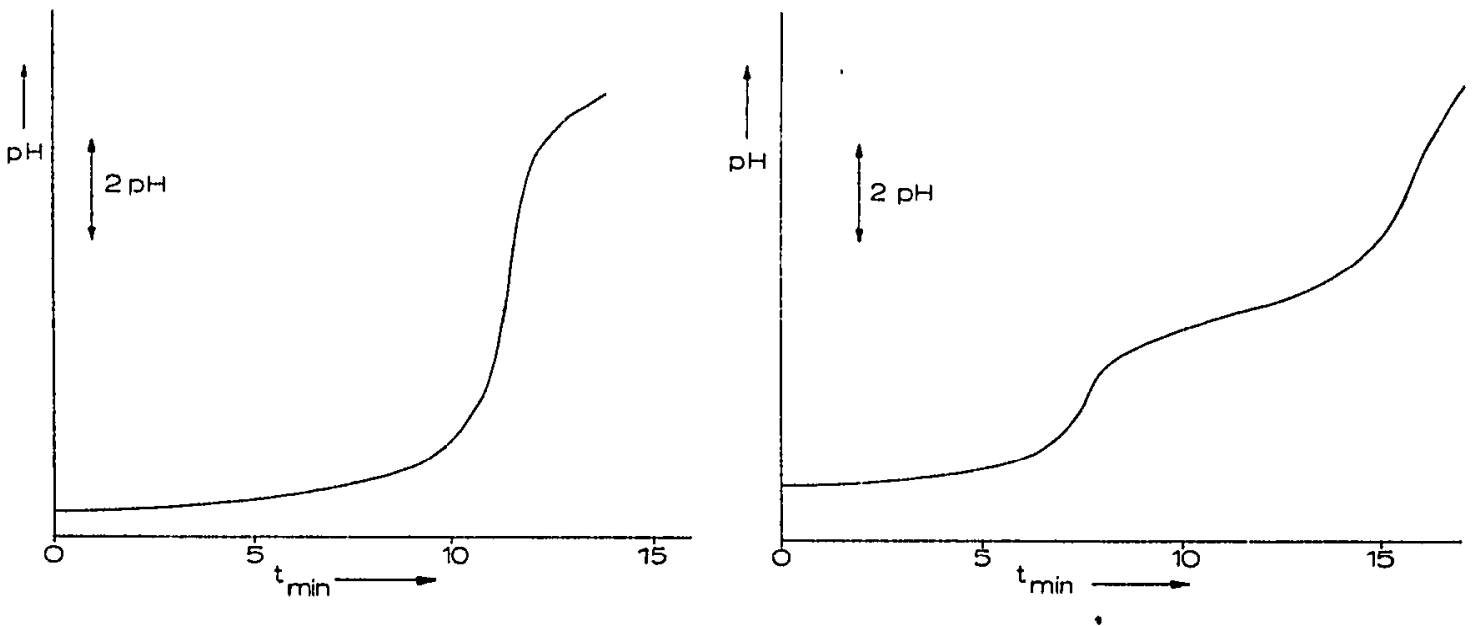

Fig. 2. Curve for the coulometric titration of $6.85 \mu$ eq of 2,4-dinitrobcnzcnesulfonic acid in $m$-cresol. Current, $0.965 \mathrm{~mA}$.

Fig. 3. Curve of the coulometric titration of a mixture of $4.60 \mu e q$ of benzenesulfonic acid and $4.80 \mu$ eq of picric acid in $m$-cresol. Current, $0.960 \mathrm{~mA}$.

TABLE I

COULOMETRIC TITRATION OF PICRIC ACID IN M-CRESOL

\begin{tabular}{lccc}
\hline peq. Added & ueq. Found & $\%$ Recovery & Current eff. $(\%)$ \\
\hline 9.44 & 9.46 & 100.2 & 99.8 \\
9.44 & 9.43 & 99.9 & 100.1 \\
9.44 & 9.40 & 99.6 & 100.4 \\
9.44 & 9.40 & 99.6 & 100.4 \\
9.44 & 9.46 & 100.2 & 99.8 \\
9.44 & 9.37 & 99.3 & 100.7 \\
9.44 & 9.43 & 99.9 & 100.1 \\
14.16 & 14.23 & 100.5 & 99.5 \\
18.88 & 18.62 & 98.6 & 101.4 \\
18.88 & 18.80 & 99.6 & 100.4 \\
\hline
\end{tabular}


TABLE II

COULOMETRIC TITRATION OF ACIDS IN m-CRESOL

\begin{tabular}{|c|c|c|c|c|}
\hline Compound & meq. Adcted & neq. Foumd & $\%$ Recovery & $\begin{array}{l}\text { Current eff: } \\
(\%)\end{array}$ \\
\hline 2,4-Dinitrobenzene sulfonic acid & 8.51 & 8.53 & 100.2 & 99.8 \\
\hline 2,4-Dinitrobenzene sulfonic acid & 8.51 & 8.53 & 100.2 & 99.8 \\
\hline 2,4-Dinitrobenzene sulfonic acid & 8.51 & 8.55 & 100.5 & 99.5 \\
\hline 2,4-Dinitrobenzene sultonic acid & 17.02 & 17.04 & 100.1 & 99.9 \\
\hline 2.4-Dinitrobenzene sulfonic acid & 17.02 & 17.04 & 100.1 & 99.9 \\
\hline Benzenesulfonic acid & 9.39 & 9.52 & 101.4 & 98.6 \\
\hline Benzenesulfonic acid & 9.39 & 9.49 & 101.1 & 98.9 \\
\hline Benzenesulfonic acid & 9.39 & 9.52 & 101.4 & 98.6 \\
\hline Benzenesulfonic acid & 9.39 & 9.62 & 102.4 & 97.6 \\
\hline Benzenesulfonic acid & 18.78 & 18.92 & 100.7 & 99.3 \\
\hline Bromochlorophenol blue & 7.78 & 7.81 & 100.4 & 99.6 \\
\hline Bromochlorophenol blue & 7.78 & 7.78 & 100.0 & 100.0 \\
\hline Bromochloropheniol blue & 7.78 & 7.77 & 99.9 & 100.1 \\
\hline Bromochlorophenol blue & 15.56 & 15.40 & 99.0 & 101.0 \\
\hline Bromochlorophenol blue & 15.56 & 15.40 & 99.0 & 101.0 \\
\hline Iodoacetic acid & 50.05 & 49.95 & 99.8 & 100.2 \\
\hline Iodoacetic acid & 50.05 & 49.80 & 99.5 & 100.5 \\
\hline lodoacetic acid & 50.05 & 50.50 & 100.9 & 99.1 \\
\hline
\end{tabular}

for the method, ten titrations of picric acid were performed (Table I). The standard deviation was $\pm 0.6 \%$. The other results are summarized in Table II. An example of a differential titration of two acids is given in Fig. 3 for the titration of a mix ture of benzenesulfonic acid and picric acid.

Titration of bases

In Fig. 4 the coulometric titration of $\mathbf{n}$-butylamine is given as an example. The results for various bases are summarized in Table III.

\section{DISCUSSION AND CONCLUSIONS}

As reported earlier ${ }^{10}$, the electrode reaction in the coulometric titration of bases is the oxidation of the $m$-cresolate ion. When $0.2 M$ urea is present in the supporting electrolyte, the important steps in the titration are:

$$
\begin{aligned}
& \text { urea }+\mathrm{Hcres}_{\text {cres }^{-} \rightarrow \text { cres }^{+} e} \text { ureaH }^{+} \text {cres }^{-} \leftrightharpoons \text { ureaH }^{+}+\text {cres }^{+} \\
&
\end{aligned}
$$

The net result is the production of ureaH ${ }^{+}$. For a successful titration, the base to be titrated should react with the $\mathrm{ureaH}^{+}$, which means that the equilibrium constant of the reaction

$$
\text { ureaH } \mathrm{H}^{+}+\mathrm{B} \leftrightharpoons \text { urea }+\mathrm{BH}^{+}
$$

should be $10^{5}$ or higher. From the $\mathrm{p} K_{\mathrm{b}}$ value of 13.8 for urea in water ${ }^{11}$, the $\mathrm{p} K_{\mathrm{a}}$ value for urea $\mathrm{H}^{+}$in $m$-cresol is estimated ${ }^{12}$ to be about 6 . Thus the method 


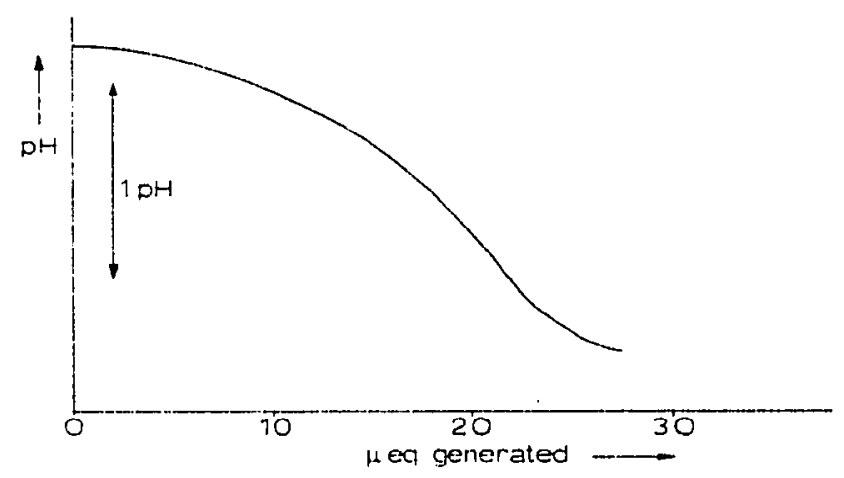

Fig. 4. Curve of the coulometric titration of $2.16 \mu \mathrm{eq}$ of n-butylamine in m-cresol. Current, $1.000 \mathrm{~m} A$.

TABLE III

COULOMETRIC TITRATIONS OF BASES IN $M$-CRESOL

\begin{tabular}{|c|c|c|c|c|c|}
\hline Compoumd & $\begin{array}{l}\text { Hequ. } \\
\text { Aclded }\end{array}$ & $\begin{array}{l}\text { Heed. } \\
\text { Fonmd }\end{array}$ & $\because$ Recotiery" & $\begin{array}{l}\text { Current } \\
\text { eff: (o) }\end{array}$ & $s_{r}{ }^{\mu}$ \\
\hline Tribenzylamine & 30.0 & 30.15 & 100.5 & 99.5 & 1.0 \\
\hline n-Butylamine & 35.61 & 34.49 & 96.8 & 103.2 & 0.8 \\
\hline Diphenylguanidine & 30.0 & 30.06 & 100.2 & 99.8 & 0.8 \\
\hline Triethylamine & 43.20 & 43.29 & 100.2 & 99.8 & 0.7 \\
\hline Tetramethylguanidine & 37.8 & 37.62 & 99.4 & 100.6 & 0.4 \\
\hline
\end{tabular}

"Mean of 10 determinations with relative standard deviation $\left(s_{r}\right)$.

is suitable for bases with $\mathrm{p} K_{\mathrm{a}}$ values above 11 in m-cresol or with $\mathrm{p} K_{\mathrm{a}}$ values above 6 in water. From Table III, it can be seen that the accuracy of the titrations increases with increasing strengths of the bases. No explanation can be offered for the low current efficiency in the determination of $n$-butylamine.

In the titrations of the acids, the electrode reaction most likely is:

2 HCres $+2 e \rightarrow \mathrm{H}_{2} \uparrow+2 \mathrm{Cres}^{-}$

as gas evolution can be observed at the working electrode during titration. The weakest acid that could be titrated was iodoacetic acid $\left(\mathrm{p} K_{\mathrm{a}}\right.$ in $m$-cresol $\left.=13\right)$.

Of the two methods used in the end-point determination, that used for the titration of bases, i.e. titration to a fixed end-point, has the advantage that the cell solution can be used more than once. However, a pre-titration is necessary to establish the value of the end-point. The accuracy of the two methods is about the same.

The authors are indebted to A. H. J. Tijhuis, Btw. who performed part of this work for his B.Sc. degree. They also thank Mrs. B. Verbeeten-v. Hettema who prepared the manuscript and Mr. R. H. Arends who made the drawings.

SUMMARY

A method is described for the coulometric titration of acids and bases in 
the solvent m-cresol. The method is suitable for bases with $\mathrm{p} K_{\mathrm{a}}$ values greater than 11 in $m$-cresol, or for acids with $\mathrm{p} K_{\mathrm{a}}$ values below 13 in $m$-cresol. Amounts of 5-50 $\mu \mathrm{eq}$ of acid or base can be determined with a relative accuracy of $\pm 1 \%$.

\section{REFERENCES}

1 J. Dubbeling. C. M. van den Enk-van Twillert and E. A. M. F. Dahmen, International Sympositum on Analytical Chemistry, Birmingham (U.K.), July, 1960.

2 B. Karlberg, Alnal. Chim. Acta, 66 (1973) 93.

3 V. J. Vajgand and R. Mihajlović. Talanta, 16 (1969) 1311.

4 W. B. Mather and F. C. Anson. Anct. Chim. Acta. 21 (1959) 468.

5 B. G. Cooksey. B. Metters. J. M. Ottaway and D. W. Whymark, Talanta, 20 (1973) 371.

6 C. A. Streuli, Anal. Chem., 28 (1956) 130.

7 G. S. Fritz and F. E. Gainer, Talanta, 15 (1968) 939.

8 C. E. Champion and D. G. Bush, Alul. Chem.. 45 (1973) 640.

9 M. Bos and E. A. M. F. Dahmen, Anal. Chim. Acta, 63 (1973) 325.

to M. Bos and E. A. M. F. Dahmen, Anal. Chim. Acta, in press.

11 R. C. Weast. Hundbook of Chemistry and Physic's, 45th edn., The Chemical Rubber Co., 1964, p. D76. 12 M. Bos and E. A. M. F. Dahmen. Anal. Chim. Acta, 57 (1971) 361. 